Public Philosophy \& Democratic Education

Volume 5 • 2016 • Issue L • pp. 87-102 • DOI: 10.14746/fped.2016.5.2.13

Participatory Methods for Information Society

Www. filozofiapubliczna.amu.edu.pl • ISSN 2299-1875

@) (reative Commons BY-NC-ND 4.0

\title{
Participation and urban policy-making in a network society - a theoretical outline on new urban governance
}

\section{Gudrun Haindlmaier}

Abstruct: Society takes place in cities and shapes them. The "city" is commonly attributed with certain objectified qualities, daily practices, perceptions and symbolic readings and is strongly linked to institutional arrangements. As various transformation forces and processes can be observed in contemporary cities, the question arises: what instruments and possibilities can be identified for steering urban structures and development by means of urban policy? The current shift away from a top-down oriented city administration and planning towards the participatory governance suggests that cities are facing new challenges and requirements that are closely associated with a political dimension. The possibilities of influencing and steering urban development by urban planning and policy and participation as one element of those control options will be discussed in this paper. In order to understand the role and scope of new urban governance the societal context that frames contemporary cities will be outlined. Starting from the characteristics of new urban governance modes it will be discussed why governance and participation can be understood as reaction to the network society and its challenges of the established nation-state based democracy, traditional power relations and legitimation of political processes and institutions.

Keywords: network society, participation, new urban governance modes

\footnotetext{
* Austrian Institute of Technology (Austria) gudrun.haindlmaier@ait.ac.at
} 


\section{Background}

As commonly agreed, urbanization is strongly linked to institutional arrangements, respective legal, political and administrative systems, and consequently to hierarchies of power. Therefore, the "city" is commonly attributed with certain objectified qualities, daily practices, perceptions and symbolic readings. As Harvey states, these "urban things" are constantly altering:

(...) the conception of the urban and of "the city" is likewise rendered unstable, not because of any conceptual definitional failing, but precisely because the concept has itself to reflect changing relations between form and process, between activity and thing, between subjects and objects. (Harvey, 1989, p. 6)

The current shift away from a top-down oriented city administration and planning towards the emergence of governance structures and approaches suggests that cities are facing new challenges (not only economic ones) and requirements that are closely associated with a political dimension. However, in times of scarce resources cities need to seek synergies, focusing on resources (e.g. promoted by visions) as well as the involvement and participation of relevant stakeholders.

Nevertheless, despite the differences between them, cities are affected by common trends and face common challenges. In particular, the key challenge they face is to develop new models of decision-making, which will increase their economic competitiveness, but at the same time reduce social exclusion. (Parkinson et al., 2004, p. 14)

The possibilities of influencing and steering urban development by urban planning and policy and participation as one element of those control options will be discussed in this paper. In order to understand the role and scope of new urban governance, one needs to outline the societal context that frames contemporary cities: throughout history, cities have always been the "engines" of society. Very often, societal developments originate in cities and therefore cities have been (and still are) social hot spots both in a positive and a negative sense. Nowadays, "Information Society" 
is the most common denomination of modern society worldwide. In a broad understanding, it comprises all visible and invisible, perceptible and imperceptible signs and traces of the so-called digital revolution both on a technological and a social level of society. The "traditional industrial society" has been transformed by new technological developments, the intensified spread and importance of mass media, increase of spatial mobility, liberalisation and acceleration of economy, globalisation (and glocalisation), etc. combined with the fact that the borders of national states are increasingly blurring. In this context, it has to be noted that communication and exchange of information is not new, but the use of information and communication technologies (ICTs) adds a new quality and increases the value of information (Banse, 2008, p. 44ff).

The concept of the Information Society originally roots in sociological and economic works of Daniel Bell and Peter Drucker in the 60ies and 70ies of the last century, who dealt with the end of industrial economy and the advent of the post-industrial society. Bell terms the "post-industrial society" by comparing the characteristics of today's society with those of an industrial and pre-industrial one. He defines the post-industrial society as a "knowledge society" with an assignment to organise the growth of technology systematically (Bell, 1979, p. 198). This implicates that planning of research and innovation plays an essential role and, consequently, knowledge dominates over office and property as source of power. Intellectual fields and research dealing with information and how organization and societal structures are affected by information became increasingly important (Ellis et al., 1999; cited in Heitzman, 2004, p. 3). As Castells states on the network issue, not only labour and (technical and social) production are affected by the transformation into a network society, but these changes alter culture and power as well. It is becoming evident that information (coupled with knowledge and skills) is the driving factor of societal (and cultural) change. As cities are places where society is compactly organized, they are influenced by these transformations in a particular manner.

Taking those transformation forces and processes into account, the question arises: what instruments and 
possibilities can be identified for steering urban structures and development by means of urban policy? From a spatial point of view three different issues determine urban development: location preference (of economy, public institutions and private households), the property market (real estate prices determine the inclusion/exclusion of certain places) and urban planning (sets a framework for the two other domains) (Häußermann \& Siebel, 2004, p. 118f). This formal framework set by urban planning is also subject to change and can be created or shaped by means of various instruments. So far (until 2-3 decades ago) the authority of formal government structures was characterized by legitimacy and accountability. Planners could rely on these structures and focus on the translation of (broad) policy objectives into distinctive spatial strategies and plans for city or neighborhood development. The spatial scope was orientated towards integrated socio-spatial relation within delimited territories. Nowadays these structures and practices have become much more complex and interconnected and "authority power" is more and more forced to give way to "network power" (Healey, 2005, p. 146). This complexity demands for new ways of governance and dealing with the dynamics of urban regions. As Patsy Healey documents in her analysis of contemporary European spatial planning, a first rethinking of spatiality, power, scale and place in a period of transforming urban regions and the emergence of the network paradigm can be observed. For such a change major political struggles and the altering of key planning stakeholders are required, as planning more and more has to "sell" views of space and territory based on a relational, networkbased notion and vocabulary (Healey, 2003; cited in Graham, 2005, p. 106). As planning is "persuasive storytelling about the future" (Throgmorton, 1992; cited in Hajer \& Zonneveld, 2000, p. 339), spatial planning is a political business. Thus, the respective planning culture is a manifold expression of the prevailing political culture. Planning culture can be defined "as the ways, both formal and informal, that spatial planning in a given multi-national region, country or city is conceived, institutionalized, and enacted." (Friedmann, 2011 , p. 168) This notion of planning culture discloses the embeddedness of planning acts in the respective political 
culture of countries and individual cities. Notwithstanding, Friedmann points out that this fundament of planning and culture is not engraved in stone but subject to change, e.g. challenged by globalization tendencies, just to name one (Friedmann, 2011, p. 168).

\section{Urban (development) policy: the shiff from government to governance}

From the perspective of economic development, it is undoubted that policy action influences city characteristics and, consequently, the determinants of economic performance. If examining the term "urban policy" closely, it becomes obvious that almost all policies influence cities in one or other way. In this rather holistic perspective, urban policy is defined very broadly and serves as a general term for all governmental activities in urban areas involving planning and delivering public services as well as supporting the development of the local economy (as an essential base for the welfare of local residents in an urban society) (Blackman, 1995; cited in Oately, 1998, p. 19). A more limited approach is to focus on "area-based government-sponsored initiatives directed at the problems of economic decline and social disadvantages found in and around (...) cities" (Oately, 1998, p. 19).

At this point, a note on the shifting role and specifications of urban policy in the last decades needs to be made. Within recent years, the role of urban policy has changed and, increasingly, aspects such as the positioning in the competition and city marketing are seen as tasks of a city administration and urban planning with respect to urban competition (see Jensen-Butler, 1997). Urban politics, city marketing and image of cities are linked together, thereby providing a linkage for (alternative) urban development policies by means of governance tools that address image building, local identities and participation. Although the concepts of a competitive city, especially in Marxist approaches on urban competition, indicate that urban development can be attributed to purely material interests and factors, this perspective is limited. The currently existing mix culture, institutions and power relations enables nations and cities 
to realize the patterns of action (within a capitalist setting) in a fundamentally different manner (Strom \& Mollenkopf, 2004, p. 285).

According to Begg, the aim of urban policy is to enable the city to adapt and to boost the cities competitive performance in a changing (economic) environment (Begg, 1999, p. 804). Especially as cities are influenced by the (inter) national economy, the performance of the urban systems has significant links to national competitiveness as explained in the beginning. Thereby, Begg identifies two important emerging demands on urban policies: first, globalisation as limiting factor to the freedom of action for governance and, second, the changes of organisation of production become manifest by the simultaneous raise both in (new form of) cooperation and competition. In his analysis of British cities, Oatley identifies a "shift from local government to local governance" in urban policy (Oately, 1998, p. 17). New organizational habits, new practices, networks and institutional arrangements have altered the self-concept of governmental and planning institutions/work, and, consequently, the form and possibilities of interaction with the public (transparency issues, open data etc.) as well as the sequence of planning and steering processes. As Beauregard (2005, p. 30) argues,

the comprehensive-rational approach associated with the planned city has lost favor over the last few decades and been replaced by a more democratic, de-centered, flexible, and citizen-driven model of planning.

As indicated above there is a shift from traditional topdown instruments of government planning towards cooperative and coordinative methods of governance. It is argued that, in many cases, regulation, control and comprehensive centralistic planning has hindered dynamic urban development (Healey, 2005; cited in Sehested, 2009, p. 246). Anyway, the control function of urban planning and regulatory functions by means of land use plans etc. does not disappear, but is supplemented. The urban planning process is altering and therefore the (creative and flexible) combination of different strategies is necessary nowadays (Frey, 2008, p. 75). What has lead to this shift? Before the recession in the $1970 \mathrm{~s}$, the state expenditures on social investment 
and collective consumption have been enforced continuously, and, consequently, the management of these state interventions has been of major importance. Griffiths defines three main characteristics of this managerialist form of government: allocation of state surpluses is more important than the attraction of private investment flows; dominance of bureaucracy over flexible and less formalised organisational modus operandi; and the predominance of a socialist welfare ideology (Griffiths, 1998, p. 42). However, social spending had to be reduced due to the economic crisis, and, as a consequence, achievements of the welfare state that have been taken for granted for so long got endangered. The crisis of fordist structures put pressure on the legitimised and well-established forms of government. They are not suitable for responding to neither the new flexible preconditions nor the need for pro-active steering of urban development; consequently, entrepreneurial modes of urban governance have emerged.

\section{Characteristics of new urban governance modes}

How the information or network society and the new characteristics of information technology as well as the changed role and perception of information (rights-based approaches, open data etc.) undermines long-established strategies of urban government, planning and traditional policies can be shown by an example given by Heitzman in his analysis of Bangalore (India):

organizational interaction based on the manipulation of data sets and multimedia presentations within a network of cooperating offices challenged the long-established autarchy of (...) authorities. (Heitzman, 2004, p. 91)

This indicates that new approaches are needed to replace or at least complement the established forms of government. But what are the specificities of this new governance and is it really something new? In any case, governance (in opposition to government) follows a different understanding of space, namely that spatial structures are socially constructed and formed by social actions. This opposes 
the "space as container-principle" following the credo that planning is done on a tabula rasa and that cities can be "built" (Frey, 2008, p. 76f). However, it needs to be noted that there is a wide spectrum of various concepts of governance in many different disciplines with (slightly) different meanings. Usually they are either focused on actors or institutions but both approaches have in common that they "share a focus on phenomena that affect the nexus between spatiality and public action" (Gualini, 2005, p. 285). Governance can be seen as co-operative form of (public) steering involving public and private actors, different levels and institutions of administration or other political actors. For that matter, governance is based on the assumption that effective political steering cannot be done by the nation state on its own, but market mechanisms and self-organization as alternatives and amendments to the established (hierarchical) system (Frey, 2008, p. 79).

Governance indicates a new kind of social-political steering logic in the public sector characterised by a differentiated and multicentred political system with a mix of private and public actors participating directly in the decision making process without any clear hierarchic relation between the many centres and actors. (Sehested, 2001; cited in Frey, 2008, p. 80)

It is important to note that the rise of governance as alternative to government is not about the withdrawal of institutions or the promotion of a (neo)liberal state model based on privatization and deregulation. Governance is about new modes of socio-economic regulations in order to ensure effective performance and to mediate between conflicting interests (Gualini, 2005, p. 286). Consequently, this conveys that cities now have more possibilities and potentials for steering urban development and positioning as they now can integrate local forces and actors more easily and quicker than within rigid, hierarchical regulation structures and steering processes. On the one hand, these findings tie up with the research on the politics of scale and on the other hand with the regulation approach, which shows that traditional models of political order and prevalent modes of state capitalism are challenged by transnationalisation and globalisation. Therefore, new modes of governance are an answer to these 
developments of changing modes of production and accumulation (Jessop, 2000; Swyngedouw, 1997; cited in Gualini, 2005 , p. 287) which put emphasis on the ability of the local state institutions to perform socio-economic tasks (Gualini, 2005, p. 287):

the sociology of governance is intrinsically part of a thinking that attempts to integrate economic, political and social changes at different scales, while privileging access through the territorial level. (Le Galès, 2002, p. 13; cited in Gualini, 2005, p. 288)

This reveals that governance is an instrument of a neoliberal spatial development reacting to the fact that regulations from above (made behind one's desk) do not work out as intended, but the involvement of stakeholders is seen as factor of success. Cooperative approaches help to identify the goals and then to achieve them. This again points out the specific local dimension of governance and the rescaling of public action towards urban and regional governmental activity. Thereby, Harding identifies three ideal-typical patterns of local governance such as the shift of welfare or distributive modes to localized supply-side measures; the increasing importance of locally based and product-orientated governing arrangements replacing the nationally based process-oriented ones; and the rise of horizontal integration, flexibility, networking and problem solving activities focusing on the realization of (economic) potentials by collaboration and strategic competition away from standardized rules and clear lines of authority and vertical integration (Harding, 1997, p. 295; cited in Gualini, 2005, p. 288). Identifying the spatial scale of these changes "[...] goes beyond the constraints of acting locally in a global world [...]; rather it is related to the redefining of the scales involved in the local dimension of governance. Far from representing an objective shift in spatial scales, this redefinition relates to a multiplicity of scalar rationales, and depends on how these frame local perceptions and strategies." (Gualini, 2005, p. 290; emphasis in original) Regardless of the respective scale, the following three important areas of methods and instruments of urban governance can be pointed out:

- Participation has become a central component of inclusive urban development. It is not just about informing the involved actors, but about encouraging active 
involvement of actors. Cities show up with very different strategies on enforcement of participation, mobilization of actors and their empowerment, but at least the aim is to foster an urban culture of participation, enable collective sensemaking and learning (Frey, 2008, p. 80f; Gualini, 2005, p. 289f). Frequently, participation is targeted on the outside, but not on the inside, which means that participation is neglected with respect to administrative structures, the inclusion of employees in urban management institutions and their active embedding into networks (Frey, 2008, p. 82).

- Territorial innovation models are regional science approaches trying to explain why local resources and potentials are still competitive advantages for companies, regions or cities despite globalization tendencies. These approaches analyse the production of a unique selling proposition (see discussion on urban competitiveness and urban entrepreneurialism). They are referred to as theoretical-institutional approaches and aim at emphasizing the importance of knowledge innovation in the context of the transition from Fordism to post-Fordist social structures. By means of cooperative bottom-up steering mechanisms, networking, clustering of businesses and local developments as well as the mobilization of local potentials can be triggered (Frey, 2008, p. 83f; Gualini, 2005, p. 289).

- Strengthening of self-organization and self-management, flexibility in planning processes by combining formal and non-formal elements require a paradigm shift and an altered (self-) understanding of territorial planning (see Frey, 2008, p. 87ff). However, it is important that self-regulation or self-organization is not to be confused with laissez-faire, as Patsy Healey indicates: "Governance practices would encourage self-management and self-regulation, but without downloading responsibility for skilled tasks such as maintaining financial accounts and ensuring compliance with necessary regulations." (Healey, 2004, p. 17; cited in Frey, 2008, p. 96)

Based on these specific possibilities and areas of governance the previously discussed difference to government 
becomes even more clear. In order to find new answers to the crisis of government bottom-up replacing top-down planning, networking and co-operation are named as upcoming instruments. The changing role of the (nation) state institutions away from hierarchies and traditional authoritative structures leads to a new understanding of policy making, "e.g. from that of a provider to that of an enabler; from that of initator to mediator and facilitator; from pivot to gatekeeper or arbitrator; from manger to policy entrepreneur" (Gualini, 2005, p. 287). Having the focus on "the particular division of labor between the market, social structures, and political structures" (Le Galès, 2002, p. 14; cited in Gualini, 2005, p. 287) reveals the need of nation states and especially cities for instruments and policies focused on competitiveness, entrepreneurialism and participation in contrary to traditional managerialism.

\section{Discussion - Governance and participation as reaction to network society}

The information and network society challenges the established nation-state based democracy, traditional power relations and legitimation of political processes and institutions. However, power does not disappear within networks, but it is altered. Therefore, "power" may not be an appropriate term anymore but rather needs to be replaced by the ability to integrate oneself into networks and make use of them:

Perhaps the question of power, as traditionally formulated, does not make sense in the network society. In the world of networks, the ability to exercise control over others depends on two basic mechanisms: the ability to program/reprogram the network(s) in terms of the goals assigned to the network; and the ability to connect different networks to ensure their cooperation by sharing common goals and increasing resources. (Castells, 2004, p. 32)

From this follows, that cities need to develop or activate capacities and potentials to position themselves in networks at various scales, even more since there is a shift of power relations towards diversity and diffusion. New forms of governance and strategic planning have to be established under these preconditions (Healey, 2005, p. 153). Because 
of these fundamental societal changes these new forms of policy and strategic planning must not be simply "added on" but have to be embedded into systems and networks (Hajer \& Zonneveld, 2000, p. 352). This opens up points of contact for the promotion of cooperative forms of urban planning/governance and provides theoretically substantiated, reasonable arguments why they might be an appropriate answer to changed societal conditions and increased pressure by urban competition. Government changes from traditional top down government planning based on "rational" calculations, linear models and hierarchical structures to a networked, active, cooperative, creative and participative governance (accompanied by complex, non-projectable, intrinsically dynamic processes and results).

There is an explicit link between patterns of governance and networks as "governance refers to self-organizing, inter-organizational networks" (Rhodes, 1996, p. 660; cited in Gualini, 2005, p. 292). As the network society tends to develop flexible organizational forms and citizens capable of creating their own action-environment, it is to be assumed that governance will be a meaningful and legitimized form of steering urban development in the future. As urban planning "is increasingly exercised in a fragmented governance system consisting of numerous policy networks that stretch across public and private boundaries (...) and across levels of public decision making" (Sehested, 2009, p. 247), instruments taking various interests into account and aiming for consensus become important. Consequently, principles of interdependence, negotiation and trust are basic governance principles in a network society (Rhodes, 1997; cited in Sehested, 2009, p. 247). Thereby, as (strategic) urban "planning is action laid out in advance" (Mintzberg, 1994, p. 7; cited in Elcock, 2008:79), it helps to reduce uncertainty and allows for dealing with an increasingly intertwined and interconnected society and economy. Due to changes in spatial patterns and demand (both in economic as well as socio-individual dimensions) it is clear that strategic planning is an active task that has to operate in a network society with flexible instruments allowing for interconnection, context-sensitivity (see e.g. Radzik-Maruszak \& Batorova, 2015) and various scalar 
re-configurations. Generally spoken, scaling gains importance and is increasingly understood as (socially) configured and constructed. If a city is able to operate on different scales, the integration of its local network into regional and global networks will allow for maximizing benefits from resources and interrelations of the network society.

To sum it up, cities are 'produced' by a variety of decisions at different levels and by different actors. The amount of influence and composition of these various public and private decision makers and processes varies over time, but is resulting in the transformation of the urban structure. Therefore, participation on different levels and among different stakeholder groups (and networks) is crucial in order to effectively and sustainably steer urban development as well as to legitimize urban policy and its actions.

\section{References}

Banse, G. (2008). Visionen der Informationsgesellschaft - Gestern, Heute, Morgen. In: G. Banse, A. Kiepas (Eds.), Visionen der Informationsgesellschaft 2016 (pp. 33-52). Berlin: Trafo.

Beauregard, R. A. (2005). Planning and the Network City: Discursive Correspondences. In: L. Albrechts, S. Mandelbaum (Eds.), The Network Society: A New Context for Planning (pp. 24-33). New York: Routledge.

Begg, I. (1999). Cities and Competitiveness. Urban Studies, 36(5-6), 795-810.

Bell, D. (1979). Die nachindustrielle Gesellschaft. Reinbek bei Hamburg: Rowohlt.

Blackman, T. (1995). Urban Policy in Practice. New York: Routledge.

Castells, M. (2004). The Network Society. A Cross-Cultural Perspective. London: Edward Elgar.

Elcock, H. (2008). Regional Futures and Strategic Planning. Regional \& Federal Studies, 18(1), 77-92.

Ellis, D., Allen, D., Wilson, T. (1999). Information Science and Information Systems. Conjunct Subjects Disjunct Disciplines. Journal of the American Society for Information Science, 50(12), 1095-1107.

Frey, O. (2008). Die Amalgame Stadt. Orte. Netze. Milieus. Wiesbaden: VS Verlag für Sozialwissenschaften.

Friedmann, J. (2011). Insurgencies: Essays in Planning Theory. London-New York: Routledge. 
Graham, S. (2005). Strategies for Networked Cities. In: L. Albrechts, S. Mandelbaum (Eds.), The Network Society: A New Context for Planning (pp. 95-109). New York: Routledge.

Griffiths, R. (1998). Making Sameness: Place Marketing and the New Urban Entrepreneurialism. In: N. Oatley (Ed.) Cities, Economic Competition and Urban Policy (pp. 41-57). London: Paul Chapman Publishing Ltd.

Gualini, E. (2005). Reconnecting Space, Place, and Institutions: Inquiring into "Local" Governance Capacity in Urban and Regional Research. In: L. Albrechts, S. Mandelbaum (Eds.), The Network Society: A New Context for Planning (pp. 284306). New York: Routledge.

Hajer, M., Zonneveld, W. (2000). Spatial Planning in the Network Society - Rethinking the Principles of Planning in the Netherlands. European Planning Studies, 8(3), 337-355.

Harding, A. (1997). Urban Regimes in a Europe of the Cities? European Urban and Regional Studies, 4(4), 291-314.

Harvey, D. (1989). From Managerialism to Entrepreneurialism: The Transformation in Urban Governance in Late Capitalism. Geografiska Annaler, 71B(1), 3-17.

Häußermann, H., Siebel, W. (2004). Stadtsoziologie. Eine Einführung. Frankfurt am Main: Campus Verlag.

Healey, P. (2003). The New Institutionalism and the Transformative Goals of Planning. In: N. Verma (Ed.), Institutions and Planning (pp. 61-87). New Brunswick, NJ: Center for Urban Policy Research.

Healey, P. (2004). The Treatment of Space and Place in the New Strategic Spatial Planning in Europe. International Journal of Urban and Regional Research, 28(1), 45-67.

Healey, P. (2005). Collaborative Planning: Shaping Places in Fragmented Societies. Basingstoke: Palgrave Macmillan.

Heitzman, J. (2004). Network City. Planning the Information Society in Bangalore. New Delhi: Oxford University Press.

Jensen-Butler, C., Shachar, A., van Weesep, J. (Eds.) (1997). European Cities in Competition. Avebury: Aldershot.

Jessop, B. (2000). The Future of the Capitalist State. Cambridge: Polity Press.

Le Galès, P. (2002). European Cities: Social Conflicts and Governance. Oxford University Press: Oxford.

Mintzberg, H. (1994). The Rise and Fall of Strategic Planning: Reconceiving the Roles for Planning, Plans, Planners. New York: Free Press.

Oatley, H. (1998). Cities, Economic Competition and Urban Policy. London: Paul Chapman Publishing Ltd.

Parkinson, M., Hutchins, M., Simmie, J., Clark, G., Verdonk, H. (Eds.) (2004). Competitive European Cities: Where Do The 
Core Cities Stand? London: European Institute for Urban Affairs.

Radzik-Maruszak, K., Bátorová, M. (2015). Citizen Participation and Engagement in Urban Governance: Perception of Finnish and Polish Local Officials. NISPAcee Journal of Public Administration and Policy, 8(1), 85-110.

Rhodes, R. A. W. (1996). The New Governance: Governing without Government. Political Studies, 44(4), 652-667.

Rhodes, R. A. W. (1997). Understanding Governance: Policy Networks, Governance, Reflexivity and Accountability. Buckingham: Open University Press.

Sehested, K. (2001). Investigating urban governance - from the perspective of policy networks, democracy and planning. In: Research Papers from the Department of Social Sciences, 1(1). Roskilde: Roskilde University.

Sehested, K. (2009): Urban Planners as Network Managers and Metagoverners. Planning Theory \& Practice, 10(2), 245-263.

Strom, E., Mollenkopf, J. (2004). Vom Reden und Handeln - Diskurs und Stadtentwicklung in New York und Berlin. In: W. Siebel (Ed.), Die europäische Stadt (pp. 284-300). Frankfurt am Main: Suhrkamp.

Swyngedouw, E. (1997). Neither Global Nor Local: "Glocalisation" and the Politics of Scale. In: K. Cox (Ed.), Spaces of Globalization: Reasserting the Power of the Local (pp. 137-166). New York-London: Guilford/Longman.

Throgmorton, J. A. (1992). Planning as Persuasive Storytelling about the Future: Negotiating an Electric Power Rate Settlement in Illinois. Journal of Planning Education and Research, 12(1), 17-31. 
